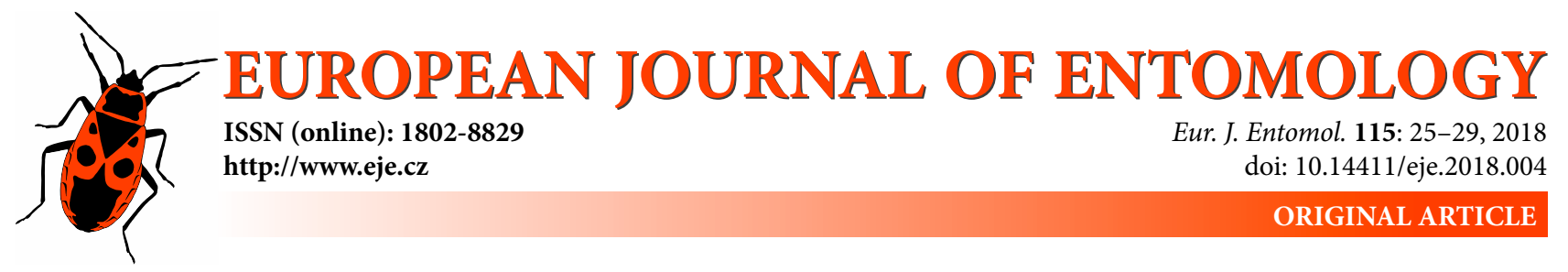

\title{
Host-plant leaf-surface preferences of young caterpillars of three species of Pieris (Lepidoptera: Pieridae) and its effect on parasitism by the gregarious parasitoid Cotesia glomerata (Hymenoptera: Braconidae)
}

\author{
Tomoko WATANABE, KeIJ NAKAMURA* and JUn TAGAWA
}

Department of Biosphere-Geosphere System Science, Faculty of Informatics, Okayama University of Science, Ridai-cho 1-1, Okayama 700-0005, Japan; e-mails: carassius_auratus_fumo@yahoo.co.jp, nakamura@big.ous.ac.jp, cotesiagl@gmail.com

\begin{abstract}
Key words. Lepidoptera, Pieridae, Pieris melete, Pieris napi japonica, Pieris rapae crucivora, Hymenoptera, Braconidae, Cotesia glomerata, parasitism rates, herbivore, host, Brassica oleracea var. capitata, Armoracia rusticana, Rorippa indica, Arabis flagellosa, leaf-surface preference, larva
\end{abstract}

\begin{abstract}
Preferences of young caterpillars of three species of Pieris ( $P$. rapae crucivora Boisduval, $P$. melete Ménétriès, and $P$. napi japonica Shirôzu) (Lepidoptera: Pieridae) for the upper and lower surfaces of the leaves of their host plants (Brassicaceae) were investigated in the laboratory. On horseradish Armoracia rusticana Gaertn. Mey. et Scherb., which was provided as a common food for three species, second and third instar larvae of the respective species preferred the lower to the upper surface of horizontally placed leaves, irrespective of whether they hatched on the upper or lower surface. First instar larvae seemed to remain on the surface on which they hatched. However, first instar larvae of $P$. melete on Rorippa indica (L.), a natural food of $P$. melete in the field, and first instar larvae of $P$. napi japonica on Arabis flagellosa Miq., a natural food of $P$. napi japonica, preferred the lower to the upper surface, just as second and third instar larvae did. To elucidate the effects of leaf-surface preference, the percentage parasitism of $P$. rapae crucivora on Arm. rusticana and Ara. flagellosa by the parasitoid Cotesia glomerata (L.) (Hymenoptera: Braconidae) was investigated. On Arm. rusticana, the percentage parasitism of the larvae on the upper surface was higher than that of larvae on the lower surface. On Ara. flagellosa, however, percentages parasitism were nearly equal on both surfaces. Leaf-surface preference by the larvae of Pieris is discussed in terms of avoidance of parasitism by the parasitoid C. glomerata.
\end{abstract}

\section{INTRODUCTION}

Pieris butterflies such as $P$. rapae crucivora Boisduval, $P$. melete Ménétriès and $P$. napi japonica Shirôzu (Lepidoptera: Pieridae) are well-known in Japan as small white butterflies. The larvae feed mainly on crucifer plants such as cabbage, radish, yellowcress and rockcress. The common habitats and principal food plants of these three species of butterfly differ (Ohsaki \& Sato, 1999). Pieris rapae crucivora larvae feed mainly on cabbage and to some degree on radish or other crucifers in open sunny fields. Pieris melete and P. napi japonica feed mainly on wild crucifers growing at the edges of forests (Ohsaki, 1980). The larvae of $P$. melete occasionally feed on vegetables as do the larvae of $P$. rapae crucivora. Pieris napi japonica larvae are found almost exclusively on rockcress, Arabis plants. For that reason, their habitat is rather limited (Ohsaki \& Sato, 1994).

The larvae are adversely affected by predation and parasitism by many natural enemies such as spiders, bugs, paper wasps, parasitoid flies and wasps, and birds. Large larvae are expected to be at higher risk of predation than small ones; small larvae are reportedly more vulnerable to parasitoids than are large ones (Slansky, 1986; Van Driesche, 1988; Reavey, 1993). The gregarious parasitoid wasp Cotesia glomerata (L.) (Hymenoptera: Braconidae) attacks young Pieris larvae and strongly affects the population dynamics of Pieris butterflies, particularly P. rapae crucivora (Matsuzawa, 1958; Ohsaki \& Sato, 1990, 1994). Cotesia glomerata females seek hosts on and near feeding marks on leaves by detecting cues such as chemical substances synthesized at wounds caused by host larvae (Sato, 1979; Horikoshi et al., 1997). When being attacked by the parasitoid, $P$. rapae crucivora larvae seem to resist being parasitized by thrashing their body, sometimes spitting saliva at the attacking wasp. However, these behaviours are useless if performed by first or second instar larvae, which are regarded as the principal hosts of C. glomerata (Matsuzawa, 1958), as in P. brassicae (L.) (Johansson, 1951;

\footnotetext{
* Corresponding author; e-mail: nakamura@big.ous.ac.jp
} 
Slansky, 1986). Apparently, the deterrent behaviours of small larvae are ineffective against attacking parasitoids. However, the small larvae have a means of reducing their risk of being parasitized. Tagawa et al. (2008) report that young, 1st-3rd instar larvae on cabbage leaves prefer the lower to the upper surface, although 4th-5th instar larvae show no such leaf-surface preference. The lower-surface preference exhibited by young larvae is regarded as a behavioural mechanism for avoiding parasitism because the percentage parasitism of the caterpillars on the lower surface is lower than that of caterpillars on the upper surface (Tagawa et al., 2008).

Parasitism avoidance in the three Pieris species is reported by Ohsaki \& Sato $(1990,1994)$ as an ecological or an immunological mechanism, but they did not consider the behaviour of host larvae. Such behaviour might serve as an added avoidance mechanism against parasitoids, as evidenced in $P$. rapae crucivora, if young caterpillars of $P$. melete and $P$. napi japonica show a preference for a particular leaf surface when feeding on their food plants. This study was designed to ascertain whether or not leaf-surface preference exists in young caterpillars of three species of Pieris. In addition, the effect of the larvae feeding on different leaf surfaces on parasitism by the parasitoid wasp $C$. glomerata was determined.

\section{MATERIALS AND METHODS}

\section{Caterpillar}

From fields in Okayama, Japan in 2008 and 2009, eggs, larvae and adult butterflies of three species of Pieris were collected: $P$. rapae crucivora $(P r)$, P. melete $(P m)$ and $P$. napi japonica $(P n)$. Eggs were allowed to hatch at room temperature in the laboratory. Newly hatched larvae and larvae collected in the field were reared at room temperature, principally on their food plants (Brassica oleracea var. capitata, Rorippa indica and Arabis flagellosa, respectively) in $350 \mathrm{ml}$ plastic cups until pupation or parasitoid egression, with absorbent paper placed beneath the lids. Occasionally, the larvae were offered horseradish (Armoracia rusticana) leaves. After pupation, pupae of each species were put in a butterfly cage $(1 \times \mathrm{w} \times \mathrm{h}=130 \times 49 \times 136 \mathrm{~cm})$ placed in a room. Adult butterflies that emerged from these pupae were fed a dilute solution of honey.

\section{Parasitoid}

Parasitoids were obtained from parasitized larvae of $P$. rapae crucivora collected in the field. Within a day after egression from the hosts, the cocoon clusters of C. glomerata were put in $30 \mathrm{ml}$ vials and kept at $20^{\circ} \mathrm{C}$ under a $16 \mathrm{~L}: 8 \mathrm{D}$ photoperiod. To assure mating after adult emergence, both sexes were kept together in the vials for more than 3 days with a drop of honey and water. Then, females were allowed to parasitize young P. rapae crucivo$r a$ larvae. These artificially parasitized hosts were reared under the conditions described above.

\section{Food plants of Pieris}

Cabbage, B. oleracea var. capitata, and horseradish, Arm. rusticana, leaves were collected from the field. Variable leaf yellowcress, $R$. indica, and rockcress, Ara. flagellosa, were collected from the field and were planted individually in small pots $(8 \times 8$ $\times 8 \mathrm{~cm}$ ). Immediately after collection, all eggs and animals on their leaves were removed carefully. Leaves of $R$. indica and Ara. flagellosa were smaller and softer than those of horseradish or cabbage.

\section{Leaf-surface location of three Pieris specis larvae on Arm. rusticana}

In the field, the three Pieris butterflies were observed to oviposit on horseradish leaves. Therefore, to collect new eggs of each Pieris species, fresh horseradish leaves, Arm. rusticana, of ca. $15 \mathrm{~cm}$ in length were placed in a butterfly cage in which the butterflies of one species were flying. Eggs on a randomly chosen surface were removed; those on the other surface were left to ascertain whether Pieris larvae preferred the upper or lower surface of the leaves. The number of eggs left on a single leaf was set as five. Each of these leaves was kept horizontally with the egg surface either facing up or down in a transparent plastic case (22 $\times 16 \times 12 \mathrm{~cm})$ at room temperature. The difference between adaxial and abaxial surfaces was ignored because the larvae did not discriminate between anatomical surfaces (Tagawa et al., 2008; prelim. obs.). One day after hatching, the first instar larvae on the respective surfaces were counted. Thereafter, the larvae on each leaf surface were counted on the day after each larval moult until the fourth instar. Unhealthy or dead larvae were excluded from the count. Horseradish leaves were exchanged with fresh leaves of similar size every other day. When changing leaves, each larva was allowed to move freely to new leaves.

\section{Leaf-surface location of $\boldsymbol{P}$. melete larvae on $\boldsymbol{R}$. indica}

Several pots of $R$. indica, a natural food of $P$. melete larvae, were placed in the butterfly cage of $P$. melete to collect new eggs. After harvesting leaves, eggs on one surface of the harvested leaves were removed. Those on the other surface were left intact. The number of eggs left on a single leaf was set as $1-3$. The petiole of each leaf was wrapped with a water-moistened cotton ball. Then the leaf was kept horizontally in a $1500 \mathrm{ml}$ plastic cup at room temperature with the egg surface facing either up or down. Thereafter, the same procedure as that described above was performed.

\section{Leaf-surface location of $P$. napi japonica larvae on Ara. flagellosa}

Several pots of Ara. flagellosa, an ordinary food of P. napi japonica larvae, were placed in the butterfly cage of $P$. napi japonica to collect new eggs. After removing eggs from one surface of the leaves, each pot was placed on a water-moistened cotton sheet in a $1500 \mathrm{ml}$ plastic cup and kept at room temperature. The number of eggs left on a single leaf was set as $1-3$. Thereafter, the same procedure as that described above was performed.

\section{Parasitism differences between the leaf surfaces}

Oviposition-experienced, mated females of C. glomerata, younger than 7 days old, were used in the parasitism experiments. The experienced females were prepared by offering young $P$. rapae crucivora larvae once within a day before the experiment. As hosts in this parasitism experiment, $P$. rapae crucivora larvae were provided because they were the most easily obtained.

To examine the parasitism difference between the leaf surfaces of Arm. rusticana, ca. 5 larvae of first, second, or third instar $P$. rapae crucivora were put on the upper or the lower surfaces of the leaves. Each leaf was then placed horizontally in a transparent plastic case $(22 \times 16 \times 12 \mathrm{~cm}) 4 \mathrm{~cm}$ above the bottom of the case. A female parasitoid was then introduced into this case and was allowed to attack the hosts freely for $24 \mathrm{~h}$ at room temperature. After removing the wasp, the host larvae were collected, irrespective of their position, and were reared under standard conditions. This procedure was replicated 2-4 times for each setting. Larvae that died during rearing were dissected under a binocular micro- 


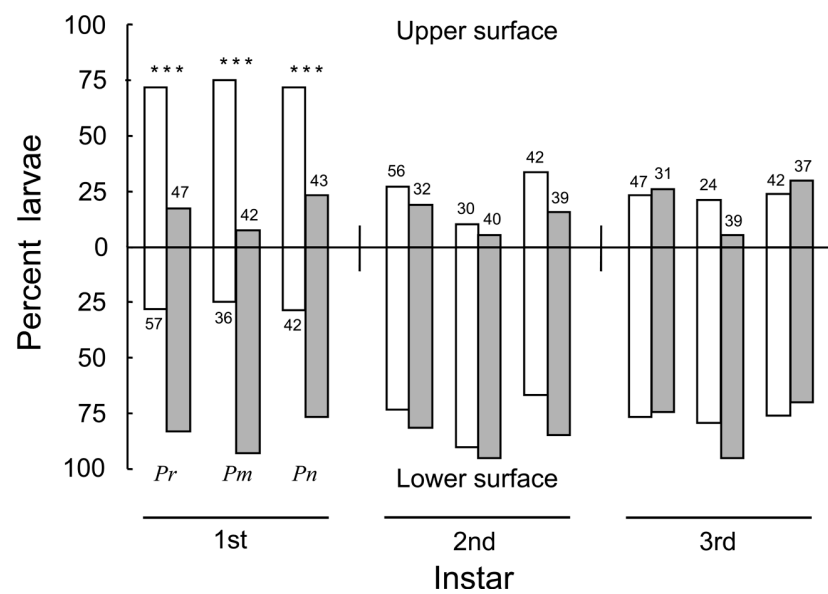

Fig. 1. Leaf surface locations of 1st-3rd instar larvae of three species of Pieris on horseradish leaves. The eggs hatched on the upper (white bars) or the lower (grey bars) surface: $\mathrm{Pr}-\mathrm{P}$. rapae crucivora; $P m-P$. melete and $P n-P$. napi japonica. Figures associated with the bars are the numbers of larvae. For every species, distribution patterns of first instar larvae are significantly different between the groups $\left(X^{2}\right.$-test: $\left.{ }^{* \star *} p<0.001\right)$.

scope. Then parasitoid eggs and larvae were counted. For larvae that yielded parasitoids, the cocoons were counted. Dead hosts were dissected to ascertain the number of parasitoid larvae that failed to egress.

Parasitism of P. rapae crucivora larvae on Ara. flagellosa was also examined. Nearly five larvae of first, second, or third instar $P$. rapae crucivora were put in a small pot $(\mathrm{ca} .300 \mathrm{ml})$ on the upper or lower surfaces of the leaves of plants of Ara. flagellosa. Each pot was then placed in a plastic case $(22 \times 16 \times 12 \mathrm{~cm})$. Thereafter, the same procedure as that described above was performed and replicated 2-4 times for each setting.

\section{Statistical analyses}

Distributions of larvae on the leaf surfaces and percentage parasitism of larvae on leaf surfaces were analyzed using $\chi^{2}$-tests. Clutch sizes of $C$. glomerata females were examined using a Mann-Whitney U-test (Zar, 1999).

\section{RESULTS}

\section{Leaf-surface location of three Pieris species larvae on Arm. rusticana}

For every Pieris species, when the eggs hatched on the lower surface of an Arm. rusticana leaf, more than 75\% of the first instars remained on the lower surface for one day after hatching (Fig. 1). Distribution patterns of the three species were not different $\left(\chi^{2}=4.2\right.$, d.f. $=2$, ns $)$. When the eggs hatched on the upper surface, more than $70 \%$ of the first instar larvae of every species remained on that surface, as they do when they hatched on the lower surface. Distribution patterns were not different among the three species $\left(\chi^{2}=0.1\right.$, d.f. $=2$, ns $)$. First instar larvae of every Pieris species showed a tendency to remain on the surface where they hatched. Therefore, for all species, the distribution patterns of first instar larvae were significantly different between the groups $\left(P r, \chi^{2}=31.2 ; P m, \chi^{2}=37.7 ; P n, \chi^{2}\right.$ $=19.8$; all d.f. $=1, p<0.001)$.

After the first moult, however, most second instar larvae of all species remained on the lower surface. Accordingly, the significant differences in the distribution patterns be- (a)

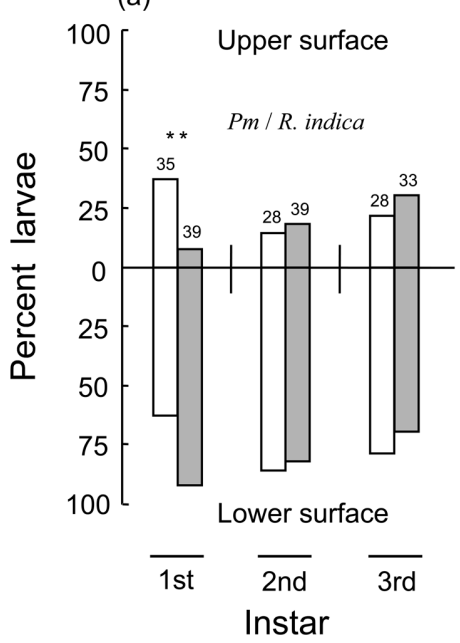

(b)

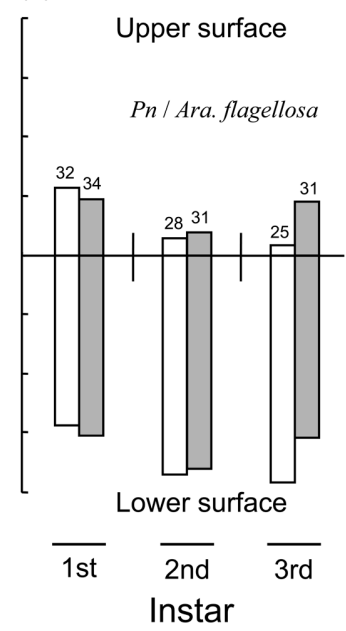

Fig. 2. Leaf surface locations of 1st-3rd instar larvae of $P$. melete on $R$. indica (a) and of $P$. napi japonica on Ara. flagellosa (b). The eggs hatched on the upper (white bars) or the lower (grey bars) surface: $P m-P$. melete and $P n-P$. napi japonica. Figures associated with the bars are the numbers of larvae. Distribution patterns of first instars of $P$. melete on $R$. indica are significantly different between the groups $\left(x^{2}\right.$-test: $\left.{ }^{* *} p<0.01\right)$.

tween the surfaces where they hatched disappeared thereafter for every species. The second and third instar larvae showed a lower-surface preference $\left(2 \mathrm{nd}-\operatorname{Pr}, \chi^{2}=24.0\right.$; $P m, \chi^{2}=51.4 ; P n, \chi^{2}=20.8$; third $-P r, \chi^{2}=20.5 ; P m, \chi^{2}=$ 38.1; $P n, \chi^{2}=17.3$; all d.f. $=1, p<0.001$ ).

\section{Leaf-surface location of $P$. melete larvae on $R$. indica}

When the eggs of $P$. melete hatched on the lower surface of $R$. indica leaf, more than $90 \%$ of the first instars remained on the lower surface for one day after hatching (Fig. $2 \mathrm{a} ; \chi^{2}=27.9$, d.f. $=1, p<0.001$ ). However, when the eggs hatched on the upper surface, fewer than $40 \%$ of the first instars remained on the upper surface, indicating there was a tendency not to remain stationary $\left(\chi^{2}=2.3\right.$, d.f. $=$ $1, \mathrm{~ns})$. Nevertheless, the distribution patterns of first instar larvae were significantly different between the groups $\left(\chi^{2}=\right.$ 9.4, d.f. $=1, p<0.01)$.

After moulting, P. melete larvae showed a lower-surface preference, irrespective of whether they hatched on the upper surface or on the lower surface. More than $70 \%$ of larvae remained on the lower surface $\left(2 \mathrm{nd}, \chi^{2}=30.2\right.$; and 3rd, $\chi^{2}=13.8$; d.f. $\left.=1, p<0.001\right)$.

\section{Leaf-surface location of $P$. napi japonica larvae on Ara. flagellosa}

When the P. napi japonica eggs hatched on the lower surface of Ara. flagellosa leaves, more than $70 \%$ of the first instar larvae remained on the lower surface one day after hatching (Fig. 2b). However, when the eggs hatched on the upper surface, less than $30 \%$ remained on the upper surface. Therefore, for first instar larvae, the distribution patterns did not differ according to the surfaces on which they hatched $\left(\chi^{2}=0.2\right.$, d.f. $\left.=1, \mathrm{~ns}\right)$. Young larvae of $P$. napi japonica on Ara. flagellosa leaf showed a lower-surface 
Table 1. Parasitism by Cotesia glomerata of young Pieris rapae crucivora larvae placed on the upper and lower surfaces of horseradish Armoracia rusticana (a) and rockcress Arabis flagellosa (b) leaves for 1 day. Figures in parentheses are the numbers of parasitized larvae. Figures in brackets are the proportions parasitized; $n$ denotes the sample size.

\begin{tabular}{|c|c|c|c|c|}
\hline \multirow{2}{*}{$\begin{array}{l}\text { Larval } \\
\text { stadium }\end{array}$} & \multicolumn{2}{|r|}{ Upper surface } & \multicolumn{2}{|r|}{ Lower surface } \\
\hline & $n$ & $\begin{array}{l}\text { No. eggs laid in a host } \\
\text { Mean } \pm \text { SD }\end{array}$ & $n$ & $\begin{array}{l}\text { No. eggs laid in a host } \\
\text { Mean } \pm \text { SD }\end{array}$ \\
\hline \multicolumn{5}{|c|}{ (a) Armoracia rusticana } \\
\hline $1 \mathrm{st}$ & 19 & $41.5 \pm 18.6(6)$ & 10 & $40.8 \pm 16.5(5)$ \\
\hline 2nd & 19 & $29.5 \pm 13.8(13)$ & 15 & $23.8 \pm 5.3(4)$ \\
\hline 3rd & 15 & $26.7 \pm 18.2(6)$ & 19 & $52.0 \pm 46.7(2)$ \\
\hline Total $^{1}$ & 53 & $31.7 \pm 16.4(25)[0.47]$ & 44 & $36.6 \pm 21.4(11)[0.25]$ \\
\hline \multicolumn{5}{|c|}{ (b) Arabis flagellosa } \\
\hline $1 \mathrm{st}$ & 20 & $48.0 \pm 28.9(16)$ & 16 & $42.2 \pm 25.1(9)$ \\
\hline 2nd & 18 & $37.2 \pm 4.7(6)$ & 20 & $36.9 \pm 11.2(8)$ \\
\hline $3 r d$ & 14 & $28.4 \pm 8.0(5)$ & 10 & $35.2 \pm 19.7(5)$ \\
\hline Total & 52 & $42.0 \pm 23.6(27)[0.52]$ & 46 & $38.7 \pm 19.1(22)[0.48]$ \\
\hline
\end{tabular}

${ }_{1}^{1}$ Proportions parasitized differ between the leaf surfaces ( $X^{2}$-test: $p<0.05)$.

preference $\left(1 \mathrm{st}-\chi^{2}=15.5 ; 2 \mathrm{nd}-\chi^{2}=40.7 ; 3 \mathrm{rd}-\chi^{2}=28.6\right.$; all d.f. $=1, p<0.001)$.

\section{Differences in the parasitism on the different leaf surfaces}

\section{Larvae on Arm. rusticana}

When 1 st-3rd instar larvae of $P$. rapae crucivora were put on the upper surface of an Arm. rusticana leaf, the percentages of first, second, and third instars parasitized were, respectively, 32\% (6/19), 68\% (13/19) and 40\% (6/15). Nearly half of all larvae $(47 \%, 25 / 53)$ were parasitized (Table 1a). However, when larvae were put on the lower surface, the percentages parasitism of first, second and third instars were, respectively, 50\% (5/10), 27\% (4/15) and $11 \%(2 / 19)$. In total, $25 \%(11 / 44)$ of larvae were parasitized. The percentage parasitism of all larvae on the upper surface was significantly higher than that of larvae on the lower surface $\left(\chi^{2}=5.1\right.$, d.f. $\left.=1, p<0.05\right)$. The number of eggs laid in a host were equal for both surfaces (MannWhitney U-test: ns), but very variable.

\section{Larvae on Ara. flagellosa}

When $P$. rapae crucivora larvae were put on the upper surface of Ara. flagellosa leaves, the percentages parasitism of first, second, and third instars were, respectively, $80 \%(16 / 20), 33 \%(6 / 18)$ and $36 \%(5 / 14)$. More than half of all larvae $(52 \%, 27 / 52)$ were parasitized (Table $1 \mathrm{~b}$ ). When larvae were put on the lower surface, the percentages parasitism of first, second, and third instars were, respectively, 56\% (9/16), 40\% (8/20) and 50\% (5/10). Nearly half of all larvae $(48 \%, 22 / 46)$ were parasitized. No significant difference in percentage parasitism was recorded between the upper and lower leaf surfaces $\left(\chi^{2}=0.2\right.$, d.f. $=$ $1, \mathrm{~ns})$. The numbers of eggs laid in a host were inferred as equal on both surfaces (ns) and very variable.

\section{DISCUSSION}

On horseradish leaves, first instar larvae of three Pieris species showed a tendency to remain on the surface on which they hatched. After moulting, however, the larvae of all species showed a preference for lower surfaces. The tendency of recently hatched larvae not to move and the degrees of lower-surface preference of 2 nd-3rd instar larvae are similar in the three species (Fig. 1). For P. rapae crucivora on cabbage leaves, Tagawa et al. (2008) report the same behaviour of $1 \mathrm{st}-3 \mathrm{rd}$ instar larvae as observed in this study. The tendency of first instar larvae to remain stationary is interpreted as showing that newly hatched larvae are weak and that they have little mobility (Tagawa et al., 2008). First instar larvae are expected to behave similarly to second and third instar larvae if food leaves are softer and/or smaller than cabbage or horseradish leaves. This idea is supported by the surface locations of the larvae on R. indica and Ara. flagellosa (Fig. 2), the leaves of which are smaller and softer than those of cabbage or horseradish. The different distribution patterns of Pieris larvae on different food plants evidently resulted from differences in the size and/or softness of their leaves. These results indicate that young larvae of species of Pieris intrinsically prefer the lower surfaces of leaves.

In the field, more than $80 \%$ of Pieris eggs are laid on the lower surface of leaves (Kobayashi, 1965; Watanabe \& Yamaguchi, 1993). Together with this fact, the lower-surface preference of young Pieris larvae is expected to result in a strong bias for the larvae to remain on the lower surface of food leaves in the field (Kobayashi, 1963), although large larvae exhibit no such tendency (Mauricio \& Bowers, 1990; Tagawa et al., 2008). The lower-surface preference is characteristic of young instar larvae.

Lower-surface preference in the young larvae of $P$. rapae crucivora on cabbage leaves is regarded as an effective way of avoiding parasitoids because the percentage parasitism of the larvae on the lower surface is less than that of larvae on the upper surface (Tagawa et al., 2008). In the present study also, young larvae on the upper surface of horseradish leaves were parasitized more easily than those on the lower surface (Table 1a), suggesting that a lower-surface preference on both cabbage and horseradish is an effective way of avoiding being encountered by parasitoids.

Nevertheless, larvae on the lower surface of Ara. flagellosa leaves do not benefit from a reduced risk of parasitism (Table 1b). A plausible reason is that the leaves of Ara. flagellosa are smaller and softer than those of horseradish or cabbage. First instar larvae of P. napi japonica on the upper surface of Ara. flagellosa leaves can move easily to the lower surface (Fig. 2b). Under such conditions, the parasitoid might also easily move to the lower surface while searching for hosts. Accordingly, the benefit for larvae of remaining on the lower surface is expected to be slight. The effectiveness of avoiding parasitoids by remaining on the lower surface of leaves is regarded as dependent on the kind of food plant. However, the difference in the food plants does not directly reflect the percentage parasitism of larvae of Pieris recorded in the field.

In the field, Ara. flagellosa is fed on mainly by P. napi japonica (Sato \& Ohsaki, 1987; Ohsaki \& Sato, 1994, 1999). The percentage parasitism of $P$. napi japonica larvae on 
Arabis plants by $C$. glomerata is reportedly as low as 0-3\% (Sato \& Ohsaki, 1987; Ohsaki \& Sato, 1994). Arabis plants normally grow below surrounding vegetation. The parasitoid-escaping efficiency is influenced strongly by the natural environment of these food plants in the field. The importance of the habitat of food plants has been discussed in terms of host-parasitoid relations. The Arabis plant environment has been shown to have a strong effect on parasitoid avoidance in $P$. napi japonica (Sato \& Ohsaki, 1987; Ohsaki \& Sato, 1994). Under natural conditions, other parasitoid-avoidance mechanisms work well for $P$. napi japonica, even if the lower-surface preference is not so effective. Moreover, in cases of occasional use of radish and cabbage by P. napi japonica (pers. obs.), lower-surface preference is expected to be effective.

Pieris melete actually escapes from $C$. glomerata by having a strong immune response (Azuma \& Kitano, 1971; Sato, 1977), which seems to be sufficient for resisting parasitism. Nevertheless, the larvae show a lower surface preference. Niogret et al. (2009) report that the growth of larvae, which have strong immune response against parasitoids, is retarded by their own immune response, resulting in small adults even if parasitism fails. Therefore, it might be beneficial that young $P$. melete larvae avoid parasitoid attacks by means of leaf-surface preference.

Our results demonstrate that young larvae of three related species of Pieris prefer lower surfaces of leaves, suggesting that this behaviour is associated with avoiding parasitoids. To elucidate the ecological meaning of this behaviour further, additional investigations must be conducted, including the host-parasitoid relations of other pierid caterpillars.

ACKNOWLEDGEMENTS. We thank K. Asakura, A. Matsushita, Y. Matsuoka, Y. Nagai, and S. Ohmori for assistance with this study.

\section{REFERENCES}

Azuma K. \& Kitano H. 1971: Experimental studies of the parasitism of Apanteles glomeratus Linné on the larvae of Pieris melete Ménétriès. - Kontyû 39: 394-399 [in Japanese with English abstr.].

Horikoshi M., Takabayashi J., Yano S., Yamaoka R., Ohsaki N. \& SATо Y. 1997: Cotesia glomerata female wasps use fatty acids from plant-herbivore complex in host searching. $-J$. Chem. Ecol. 23: 1505-1515.

Johansson A.S. 1951: Studies on the relation between Apanteles glomeratus L. (Hym., Braconidae) and Pieris brassicae L. (Lepid., Pieridae). - Norsk Entomol. Tidsskr. 8: 145-186.

KoBaYASH S. 1963: The distribution of Pieris rapae crucivora on cabbage leaves. - Jpn. J. Ecol. 13: 226-230 [in Japanese with English abstr.].

Kobayashi S. 1965: Influence of adult density upon the oviposition site in the cabbage butterfly, Pieris rapae crucivora. Jpn. J. Ecol. 15: 35-38 [in Japanese with English abstr.].
Matsuzawa H. 1958: Ecological studies on the braconid wasp, Apanteles glomeratus. - Mem. Fac. Agr. Kagawa Univ. 3: 1-125 [in Japanese with English abstr.].

Mauricio R. \& Bowers M.D. 1990: Do caterpillars disperse their damage?: Larval foraging behaviour of two specialist herbivores, Euphydryas phaeton (Nymphalidae) and Pieris rapae (Pieridae). - Ecol. Entomol. 15: 153-161.

Niogret J., Sait S.M. \& Rohani P. 2009: Parasitism and constitutive defence costs to host life-history traits in a parasitoid-host interaction. - Ecol. Entomol. 34: 763-771.

Ohsaki N. 1980: Comparative population studies of three Pieris butterflies, $P$. rapae, $P$. melete and P. napi, living in the same area. II. Utilization of patchy habitats by adults through migratory and non-migratory movements. - Res. Popul. Ecol. 22: 163-183.

OHSAKi N. \& SATo Y. 1990: Avoidance mechanisms of three Pieris butterfly species against the parasitoid wasp Apanteles glomeratus. - Ecol. Entomol. 15: 169-176.

Ohsaki N. \& Sato Y. 1994: Food plant choice of Pieris butterflies as a trade-off between parasitoid avoidance and quality of plants. - Ecology 75: 59-68.

OHSAKi N. \& SATo Y. 1999: The role of parasitoids in evolution of habitat and larval food plant preference by three Pieris butterflies. - Res. Popul. Ecol. 41: 107-119.

Reavey D. 1993: Why body size matters to caterpillars. In Stamp N.E. \& Casey T.M. (eds): Caterpillars: Ecological and Evolutionary Constraints on Foraging. Chapman and Hall, New York, pp. 248-279.

SAто Y. 1977: Experimental studies on parasitization by Apanteles glomeratus L. (Hymenoptera: Braconidae). II. Parasitization by Apanteles glomeratus L. reared in Pieris melete Ménétriès. - Appl. Entomol. Zool. 12: 330-333.

SAто Y. 1979: Experimental studies on parasitization by Apanteles glomeratus. IV. Factors leading a female to the host. Physiol. Entomol. 4: 63-70.

Sato Y. \& Ohsaki N. 1987: Host-habitat location by Apanteles glomeratus and effect of food-plant exposure on host-parasitism. - Ecol. Entomol. 12: 291-297.

SLANSKY F. JR 1986: Nutritional ecology of endoparasitic insects and their hosts: An overview. - J. Insect Physiol. 32: 255-261.

Tagawa J., Matsushita A. \& Watanabe T. 2008: Leaf surface preference in the cabbage worm, Pieris rapae crucivora, and parasitism by the gregarious parasitoid Cotesia glomerata. Entomol. Exp. Appl. 129: 37-43.

VAN DRIESChe R.G. 1988: Field measurement of population recruitment of Apanteles glomeratus (L.) (Hymenoptera: Braconidae), a parasitoid of Pieris rapae (L.) (Lepidoptera: Pieridae), and factors influencing adult parasitoid foraging success in kale. - Bull. Entomol. Res. 78: 199-208.

Watanabe M. \& Yamaguchi H. 1993: Egg cannibalism and egg distribution of two Pieris butterflies, Pieris rapae and P. melete (Lepidoptera, Pieridae) on a host plant, Rorippa indica (Cruciferae). —Jpn. J. Ecol. 43: 181-188 [in Japanese with English abstr.].

Zar J.H. 1999: Biostatistical Analysis. 4th ed. Prentice Hall, Upper Saddle River, 929 pp.

Received May 31, 2017; revised and accepted January 8, 2018 Published online January 29, 2018 